\title{
Cytokine involvement in stress may depend on corticotrophin releasing factor to sensitize ethanol withdrawal anxiety
}

\author{
Darin J. Knapp ${ }^{*}, 1,2,4$, Buddy A. Whitman ${ }^{1,4}$, Tiffany A. Wills ${ }^{1,4}$, Robert A. Angel ${ }^{1}$, David H. \\ Overstreet $^{1,2}$, Hugh E. Criswell ${ }^{1,2}$, Zhen Ming ${ }^{1}$, and George R. Breese ${ }^{1,2,3,4}$ \\ ${ }^{1}$ Bowles Center for Alcohol Studies, University of North Carolina School of Medicine, Chapel Hill, \\ NC 27599 \\ ${ }^{2}$ Department of Psychiatry, University of North Carolina School of Medicine, Chapel Hill, NC \\ 27599 \\ ${ }^{3}$ Department of Pharmacology, University of North Carolina School of Medicine, Chapel Hill, NC \\ 27599 \\ ${ }^{4}$ Department of Curriculum in Neurobiology, University of North Carolina School of Medicine, \\ Chapel Hill, NC 27599
}

\begin{abstract}
Stress has been shown to facilitate ethanol withdrawal-induced anxiety. Defining neurobiological mechanisms through which stress has such actions is important given the associated risk of relapse. While CRF has long been implicated in the action of stress, current results show that stress elevates the cytokine TNF $\alpha$ in the rat brain and thereby implicates cytokines in stress effects. In support of this view, prior TNF $\alpha$ microinjection into the central amygdala (CeA) of rats facilitated ethanol withdrawal-induced anxiety - a response that could not be attributed to an increase in plasma corticosterone. To test for a possible interaction between cytokines and CRF, a CRF1-receptor antagonist (SSR125543) administered prior to the repeated administration of TNF $\alpha$ or MCP-1/CCL2 reduced the magnitude of the withdrawal-induced anxiety. This finding provided evidence for cytokine action being dependent upon CRF. Additionally, the sensitizing effect of stress on withdrawal-induced anxiety was reduced by treating the repeated stress exposure prior to ethanol with the MEK inhibitor SL327. Consistent with cytokines having a neuromediator function distinct from a neuroimmune action, $\mathrm{TNF} \alpha$ increased firing rate and GABA release from $\mathrm{CeA}$ neurons. Thus, an interaction of glial and neuronal function is proposed to contribute to the interaction of stress and chronic ethanol. Interrupting this potential glial-neuronal interaction could provide a novel means by which to alter the development of emotional states induced by stress that predict relapse in the alcoholic.
\end{abstract}

\footnotetext{
(C) 2011 Elsevier Inc. All rights reserved.

*Corresponding Author: Darin J. Knapp, PhD. CB 7178, University of North Carolina, Chapel Hill, NC 27599, darin_knapp@med.unc.edu; Phone: 919-966-0505; Fax: 919-966-5679.

Publisher's Disclaimer: This is a PDF file of an unedited manuscript that has been accepted for publication. As a service to our customers we are providing this early version of the manuscript. The manuscript will undergo copyediting, typesetting, and review of the resulting proof before it is published in its final citable form. Please note that during the production process errors may be discovered which could affect the content, and all legal disclaimers that apply to the journal pertain.

Conflict of Interest Statement: All authors declare that there are no conflicts of interest.
} 


\section{Keywords}

corticotrophin releasing factor receptor; stress; cytokine; TNFa; amygdala; ethanol; SSR125543; SL327; electrophysiology

\section{Introduction}

Stress has long been thought to be a significant factor in the etiology of alcoholism (e.g., Breese et al., 2005a,b, 2011; Koob, 2009; Pohorecky, 1981; 1991; Sinha and Li, 2007). For example, clinical laboratory studies demonstrate that abstinent alcoholics respond with enhanced craving for alcohol (ethanol) when they are exposed to stress-related or ethanol cue-related images (Fox et al., 2007; Sinha and Li, 2007; Sinha et al., 2009). Further, anxiety and stress disorders are considerably over-represented in alcoholics, and selfmedication of these and related negative emotional states with ethanol remains a conceptual and experimental focus of both basic and clinical research (e.g., Breese et al., 2005a,b; Brady and Lydiard, 1993; Regier et al., 1990; Zhang et al., 2007). Acute and persistent vulnerability to stress both during acute withdrawal from alcohol and beyond the acute withdrawal period (i.e., during extended abstinence) may play an important role in perpetuating maladaptive drinking behavior. Results from rodent models of chronic ethanol exposure, particularly cyclic patterns of ethanol exposure and withdrawal, support the idea that progressively worsening profiles of withdrawal-like states arise and may persist over time to render subjects vulnerable to future environmental stressors and challenges (Breese et al., 2005b; Overstreet et al., 2002; Valdez et al., 2002). A number of neurobiological substrates, including those associated with GABA, serotonin, norepinephrine, and corticotrophin releasing factor (CRF) have been implicated in this vulnerability (e.g., Breese et al., 2005b; Koob, 2010; Smith and Aston-Jones, 2008). CRF, in particular, appears to be integral in acute and persistent vulnerability to stress in alcohol dependence (Huang et al., 2010; Koob, 2010; Lowery and Thiele, 2010). Recent data also implicate the cytokine/ chemokine systems in CNS sensitization (e.g., Kawasaki et al., 2008) and in the etiology of chronic ethanol-related phenotypes (Breese et al., 2008; Qin et al., 2008). For example, prior administration of LPS or cytokines/chemokines accelerates the development of anxiety-like behavior in animals subsequently exposed to ethanol and withdrawal (Breese et al., 2008). Further, profound enhancement of LPS effects on brain cytokines has been observed in rodents pretreated with chronic ethanol (Qin et al., 2008). Elevated levels of the chemokine monocyte chemotractant protein-1 (MCP-1/CCL2) have been found in several regions of the human post-mortem alcoholic brain including the amygdala (He and Crews, 2008).

Some evidence demonstrates comparable effects of CRF and cytokines on alcohol-related maladaptations and is consistent with a possible interactive role of cytokines and CRF in ethanol withdrawal phenotypes including stress vulnerability indexed by anxiety-like behavior (Breese et al., 2004; 2005; 2008; Huang et al., 2010; Overstreet et al., 2004). Further, evidence suggests that the amygdala plays a key role in these behaviors (e.g., Huang et al., 2010; Knapp et al., 2007). The experiments described herein were designed to explore the hypothesis that CRF and cytokines may work together to worsen ethanol withdrawal phenotypes through actions in specific brain regions including the amygdala. In a series of experiments, the effects of stress on brain cytokines and the effects of cytokines on neuronal physiology in the amygdala were investigated, and potential interactions of CRF and cytokines on ethanol withdrawal-related behavior attributable to functions of the amygdala were assessed. 


\section{Methods}

\subsection{Experiments}

Six experiments were conducted. Experiment 1 examined the brain's TNF $\alpha$ response to acute restraint stress relative to unstressed controls. Experiment 2 challenged the amygdala with the cytokine TNF $\alpha$ or vehicle prior to 5 days of $7 \%$ ethanol diet (ED) or control diet (CD) exposure to determine whether future ethanol withdrawal anxiety responses (reduced social interaction behavior) at $5 \mathrm{hrs}$ into withdrawal would be magnified. Experiment 3 examined the consequence of intra-amygdala TNF $\alpha$ or vehicle injections or stress on plasma corticosterone levels. Experiment 4 employed a CRF-1 receptor antagonist administered peripherally in an attempt to block effects of intracerebroventricular (ICV) cytokine/ chemokine administration (MCP-1 or TNF $\alpha$ ) enhancement of future withdrawal anxiety 24 hours after cessation of $4.5 \%$ ED drinking. Experiment 5 examined a downstream receptor effector mechanism (pERK activity) while Experiment 6 assessed the electrophysiological responses of amygdala neurons to TNF $\alpha$. Additional details of the experimental protocols for Experiments 1-5 are depicted in Figure 1.

\subsection{Animals and Housing}

Adult male Sprague-Dawley rats (180-220 g at the start of experiments, Charles River, Raleigh, NC, or Harlan, Dublin, VA) were used for behavioral studies while 13-20 day old male Sprague-Dawley rats bred in house from Charles River stock parents were used for electrophysiology. Adult rats were group housed upon arrival for up to a week prior to surgeries or entering a study. Rats were then isolate housed for the remainder of the experiments. Animal facility temperatures and humidity were maintained at $70-74{ }^{\circ} \mathrm{F}$ and 40-60\% humidity with lights on at 07:00 and off at 19:00. All adult animals received RMH3000 rat chow (TestDiets, Richmond, IN) until they were switched to liquid diets. All studies using animals were approved by the Institutional Animal Care and Use Committee at the University of North Carolina, Chapel Hill.

\subsection{Liquid Diets}

Ethanol-containing or control diets were employed as previously described (e.g., Knapp et al., 2007; Overstreet et al., 2002; Wills et al., 2008). Briefly, rats were exposed to either CD or a $4.5 \%$ or $7 \%$ ED liquid diet in a modified pair-feeding fashion for the periods described in the relevant experiments below. The diets were nutritionally complete and calorically balanced with appropriate concentrations of dextrose versus ethanol. Rats first received ICV or amygdala cannuli implants via stereotaxic surgery as applicable 3 days prior to receiving $\mathrm{CD}$ initially to adapt to the novel food source. Rats then received drug injections and then ethanol-containing diets as described below. Ethanol withdrawal was then initiated by switching rats from $\mathrm{ED}$ to $\mathrm{CD}$ on the morning of behavioral test (which occurred between 5 and 24 hours post-withdrawal). The protocol for employing the diets in the context of the experiments is shown in Figure 1.

\subsection{Surgeries}

Rats that had cannuli implanted were anesthetized with isoflurane, the skulls exposed, and holes drilled for a 26 gauge stainless steel cannula implanted into the brain to a point directly above the target region (the lateral ventricle or the central nucleus of the amygdala---CeA). Two additional holes for machine screws facilitated securing the cannuli with dental cement. The coordinates for placement of the ICV cannula tip were (in $\mathrm{mm}$ ) -0.8 AP, $-1.6 \mathrm{ML}$, and $-2 \mathrm{DV}$ based on the atlas of Paxinos and Watson (2005). For the central amygdala injections, the cannuli coordinates were $2.3,-4.5$, and -5.5 . The placements were such that during the subsequent drug injections, the injector needle 
(described below) protruded $2.5 \mathrm{~mm}$ deeper (DV) than the cannula tip for the ICV and central amygdala injections. A 32-gauge stainless steel wire plug kept the cannuli closed when not in use for injections. Animals were allowed to recover at least 3 days prior to proceeding to other treatments.

\subsection{Drugs/chemicals}

TNF $\alpha$ was recombinant rat TNF $\alpha /$ TNFSF1A (R \& D Systems, Minneapolis, MN; 10 or 100 $\mathrm{ng} / 0.5 \mu \mathrm{l}$ in each amygdala or $100 \mathrm{ng} / 5 \mu \mathrm{ICV}$ as per Breese et al., 2008), and MCP-1 was carrier-free recombinant rat (Leinco Technologies, St. Louis, MO; $100 \mathrm{ng} / 0.5 \mu \mathrm{l}$, as per Breese et al., 2008; Plata-Salaman et al., 1994;1996). Cytokines were prepared in artificial cerebrospinal fluid (aCSF) comprised of pyrogen-free sterile water containing $217 \mathrm{mM}$ $\mathrm{NaCl}, 3 \mathrm{mM} \mathrm{KCl}, 1 \mathrm{mM} \mathrm{CaCl} 22 \mathrm{H}_{2} 0,1 \mathrm{mM} \mathrm{MgCl}_{2} \cdot 6 \mathrm{H}_{2} 0,0.8 \mathrm{mM} \mathrm{Na}_{2} \mathrm{HPO}_{4} 7 \mathrm{H}_{2} 0$, and 0.2 $\mathrm{mM} \mathrm{NaH} 2 \mathrm{PO}_{4} \cdot \mathrm{H}_{2} \mathrm{O}$. ICV or amygdala injections were made over 1 minute via a 32- gauge stainless steel injector guided to the site of interest via the indwelling cannula. Injectors were left in place for 1 minute to accommodate drug dispersal at the injection site. The CRF-1 receptor antagonist SSR125543, a gift of Sanofi-Aventis (Montpellier, France), was prepared in saline with $2 \%$ Tween- 80 at $5 \mathrm{mg} / \mathrm{ml}$ and administered IP $(10 \mathrm{mg} / \mathrm{kg})$. Vehicles for all control injections were identical to those used to prepare the respective drugs. MCP-1, TNF $\alpha$, and SSR125543 were made and used immediately or stored in ready-to-use aliquots for up to 24 hours at $4^{\circ} \mathrm{C}$ or up to 3 months at $-80^{\circ} \mathrm{C}$. The MEK inhibitor SL327 (Ascent Scientific, Princeton, NJ) was prepared at $1 \mu \mathrm{g} / 5 \mu \mathrm{l}$ in aCSF containing 1\% DMSO and injected ICV. Finally, for electrophysiology, buffers/reagents are described in the relevant section below.

\subsection{Stress}

Some rats were stressed twice for 60 minutes in plastic decapicone restrainers then returned to home cages for 4.5 hours (Experiment 1) prior to sacrifice (5.5 hours after the start of stress). A second set of animals (Experiment 3) was stressed for 30 minutes and processed as described below for blood collection. Finally, others were injected with SL327 or its vehicle $30 \mathrm{~min}$ prior to two 60 -min stress sessions 7 days apart. These rats then continued in the protocol described below (Experiment 6).

\subsection{Social Interaction Test}

The social interaction (SI) test is a validated index of anxiety-like states in rats (File and Hyde, 1978; File and Seth, 2003), and this test has been adapted for general use in our laboratory (Breese et al., 2004, 2005b; Knapp et al., 2005; Overstreet et al., 2002, 2003, 2004). In the 5-minute SI test, rats of approximately similar sizes were placed into a $60 \times 60$ $\mathrm{cm}$ square black Plexiglas open field with $15 \times 15 \mathrm{~cm}$ squares marked on a clear plexiglas floor under low lighting conditions ( $30 \mathrm{~lx}$ ). The amount of aggregate time each rat was engaged in social behavior (conspecific grooming, sniffing, following, crawling over/under its partner) was recorded by a blinded observer. An elevated anxiety-like response was inferred from reduced social interaction behavior. Line crosses were also recorded as a measure of locomotor activity.

\subsection{Blood and Brain Tissue Collection}

At 45 min after intra-amygdala administration of TNFa (Experiment 3) and 15 minutes after the termination of the stress, some rats were sacrificed for trunk blood for radioimmunoassay of corticosterone. Blood was heparinized, kept on ice, then centrifuged at $2600 \mathrm{~g}$ for 10 minutes and the supernatants (plasma) collected and stored at $-80^{\circ} \mathrm{C}$ until assayed. Brain tissue for $\mathrm{TNF} \alpha$ measures were obtained following rapid decapitation, 
extraction and freezing of brains in isoflurane at $-25^{\circ} \mathrm{C}$. Sagittal cuts at the midline of each brain provided half-brains (hemispheres) of each rat that were processed for TNF $\alpha$.

\subsection{Corticosterone and TNFa Measures}

Plasma corticosterone was assayed as per the manufacturer's instructions using a ${ }^{125}$ I Rat and Mouse kit supplied by MP Biomedicals (Orangeburg, NY). Radioactivity was assessed relative to standard curves with an LKB Wallac 1282 Compugamma counter (Akribis Metrology, Worcestershire, UK). For TNF $\alpha$ measures, brain tissue was homogenized for 45 seconds in $10 \mathrm{ml}$ of homogenization buffer (20 mM TRIS, $0.25 \mathrm{M}$ Sucrose, $0.2 \mathrm{mM}$ EDTA, $10 \mathrm{mM}$ EGTA, 1\% Triton X-100) including a protease inhibitor (Roche, Cat\# 11836153 001). Homogenates were centrifuged at $12,000 \mathrm{~g}$ for 30 minutes at $4^{\circ} \mathrm{C}$ and the resultant supernatant was aliquoted and stored at $-80^{\circ} \mathrm{C}$ until analysis. ELISA kits were purchased to analyze levels of TNF $\alpha$ (RayBiotech, Inc., Norcross, GA). All ELISA experiments were performed according to manufacturer's instructions. Standard curves with levels from 0 $20,000 \mathrm{pg} / \mathrm{ml}$ were created for each cytokine using the recombinant rat cytokine provided in each kit. In addition, a BCA Protein analysis (Pierce Biotechnology, Inc., Rockford, IL) was performed to determine total protein levels for all samples. All data were collected using a Spectramax Plus384 microplate spectrophotometer (Molecular Devices, Inc., Sunnyvale, CA). Absorbance was at $450 \mathrm{nM}$ for all cytokine ELISA kits, and was $562 \mathrm{nM}$ for the BCA protein analysis. Resulting data were the normalized to total protein levels.

\subsection{Electrophysiology: Preparation of brain slices}

Sprague-Dawley rats, 13-20 days old, were anesthetized by i.p. injection of 75\% urethane and decapitated. The brains were rapidly removed and placed in ice-cold aCSF of the following composition (in $\mathrm{mM}$ ): $\mathrm{NaCl} 124, \mathrm{KCl} 3.25, \mathrm{KH}_{2} \mathrm{PO}_{4} 1.25, \mathrm{CaCl}_{2} 2, \mathrm{NaHCO}_{3} 20$, $\mathrm{MgSO}_{4} 2$, and glucose 10. Coronal sections through the CeA were cut with a vibrating tissue slicer (Vibratome, Series 1000). The slices were stored in a beaker containing aCSF gassed with $95 \% \mathrm{O}_{2} / 5 \% \mathrm{CO}_{2}$. The slices were equilibrated at least 1 hour at room temperature before starting experiments. For electrophysiological recording, the brain slice was placed at the bottom of a chamber and superfused with aCSF gassed with $95 \% \mathrm{O}_{2} / 5 \% \mathrm{CO}_{2}$ at a flow rate of $0.5-1 \mathrm{ml} / \mathrm{min}$ and the chamber maintained at room temperature $\left(21-24{ }^{\circ} \mathrm{C}\right)$. The cells in slices were visualized under IR illumination with differential interference contrast optics and a water-immersion lens $(40 \mathrm{X} / 0.80 \mathrm{~W})$, with the image shown in a monitor via a video camera.

\subsection{Electrophysiological Recording}

Electrophysiological studies were performed under either voltage-clamp at $-60 \mathrm{mV}$ in the whole-cell configuration for mIPSCs or in loose-patch configuration at $0 \mathrm{mV}$ for action potential recording using an Axopatch-1D amplifier (Axon Instruments/Molecular Devices, Sunnyvale, CA). Recording pipettes were fabricated from N 51A capillary glass (Drummond Scientific, Broomall, PA). The internal solution for voltage-clamp recording included (in mM) $\mathrm{KCl} 150, \mathrm{MgCl}_{2}$ 3.1, HEPES 15, K-ATP 2, EGTA 5, phosphocreatine 15, and $50 \mathrm{U} / \mathrm{ml}$ creatine phosphokinase, adjusted to $\mathrm{pH} 7.4$ with $\mathrm{KOH}$ and to an osmolality of 310 mosmoles/L (adjusted with sucrose). For action potential recording the $15 \mathrm{mM}$ phosphocreatine and $50 \mathrm{U} / \mathrm{ml}$ creatine were not included in the internal solution. The $\mathrm{KCl}$ was included in the solution during action potential recording to maintain baseline cell firing. For voltage-clamp recording, seals were formed on the neurons with electrodes having a tip resistance of 2-4 M $\Omega$. Data were displayed on an oscilloscope, digitized at 2 $\mathrm{kHz}$, and stored on a personal computer. Recordings were performed at room temperature in a bath where the neurons were superfused at $0.5-1 \mathrm{ml} / \mathrm{min}$. TNF $\alpha$ was dissolved in aCSF and applied by a drug perfusion pencil with a diameter of $250 \mu \mathrm{m}$ for a 2 min interval. The mIPSC rate or the rate of action potentials during the last $30 \mathrm{sec}$ period of that interval was 
compared to rate in the $30 \mathrm{sec}$ period preceding the cytokine application. In control recordings, the TNF $\alpha$ was replaced with aCSF. Control (aCSF) and TNF $\alpha$-containing aCSF solutions were delivered through Teflon tubing connected with the multi-barrel perfusion pencil positioned 150-250 m from the cells tested. Data were collected with Clampex 8.1 software (Axon Instruments) and prepared as mean \pm SEM. Action potential/firing rates or mIPSCs were computed using MiniAnalysis (Synaptosoft; Decatur, GA).

\subsection{Data Analysis}

For social interaction and locomotor scores, plasma corticosterone, and brain TNF $\alpha$, t-tests or 1-way or 2-way ANOVA were used for 2-group versus multiple-group analyses. Fisher's PLSD tests were used for comparisons of individual pairs of groups within an experiment. For electrophysiological data, pre- and post-TNF $\alpha$ action potentials/firing rates and miniinhibitory post-synaptic currents were averaged for a baseline then related to recordings made during the presence of TNF $\alpha$ by computing a change from this baseline. Similarly calculated means derived from vehicle/buffer-only exposed cells were then compared with the data from the TNF $\alpha$ exposed cells with t-tests. Group differences deemed significant at $\mathrm{p}<0.05$.

\section{Results}

\subsection{Experiment 1. Effect of Restraint Stress on Brain TNFa}

This experiment focused on collecting data on brain TNF $\alpha$ following the restraint utilized in previous experiments to sensitize ethanol withdrawal anxiety. Figure 2 depicts an approximate doubling of brain $\mathrm{TNF} \alpha 5.5$ hours after the start of 60 minutes of restraint stress relative to unstressed control rats, $\mathrm{t}(6)=3.12, \mathrm{p}<0.05$.

\subsection{Experiment 2. Effect of TNFa Microinjection into the Central Amygdala on Facilitation of Ethanol Withdrawal Anxiety}

This experiment was conducted to assess the consequences of exogenously administered $\mathrm{TNF} \alpha$ into the amygdala on behavioral consequences of subsequent chronic ethanol and withdrawal. As shown in Figure 3, there was a main effect of the ethanol exposure, $F(1,34)$, $=42.0, \mathrm{p}<0.0001$ and an interaction of ethanol exposure and drug treatment, $\mathrm{F}(1,34)=10.1$, $\mathrm{p}<0.01$. Posthoc tests revealed that by itself, TNF $\alpha$ administered to controls exerted no significant effect on future anxiety ( $p>0.05$ ), nor did vehicle injections induce an anxiety response different than control animals that had never had stereotaxic surgery and microinjections (e.g., Knapp et al., 2005). The $7 \%$ chronic ED alone modestly but significantly reduced social interaction by $27 \%$ ( $\mathrm{p}<0.05$ versus vehicle treated rats). In contrast, the combination of chronic ethanol and $\mathrm{TNF} \alpha$ markedly reduced social interaction by $66 \%$ ( $<<0.05$ versus vehicle treated rats) (Figure 3). Body weights, ethanol intakes, and locomotor behavior are shown in Table 1 .

\subsection{Experiment 3. Effect of TNFa microinjection into the Amygdala on Plasma Corticosterone}

To demonstrate the potential role of corticosterone in the effects of TNF $\alpha$, this experiment assessed plasma corticosterone levels following stress or intra-amygdala TNF $\alpha$ administration. Overall, treatment effects were significant, $F(2,15)=27.4, p<0.0001$. Figure 4 illustrates that plasma corticosterone was not altered by a TNF $\alpha$ dose 10 times that utilized for Figure 3 ( $p>0.05)$. Restraint stress produced the expected increase in corticosterone ( $p<0.05$ versus either TNF $\alpha$ - or aCSF-treated controls). 


\subsection{Experiment 4. Effect of a CRF1 Receptor Antagonist on Cytokine Facilitation of Ethanol Withdrawal Anxiety}

Previous work had suggested that the action of cytokines may depend upon CRF (Borsody et al., 2002; del Cerro and Borrrell, 1990; Kohman et al., 2007). To probe the potential interaction of CRF and cytokine systems in ethanol withdrawal-induced anxiety, this experiment included injections of CRF-1 receptor antagonist prior to the repeated weekly $\mathrm{TNF} \alpha$ treatment in an attempt to block cytokine facilitation of ethanol withdrawal anxiety. MCP-1 was also examined to confirm an earlier finding (Breese et al., 2008) and to extend the examination of CRF receptor antagonism to this chemokine. Overall, there was a significant treatment effect, $F(6,52)=8.30, p<0.0001$. Figure 5 shows the effects of a single 5 -day cycle of chronic ethanol alone (4.5\%ED) versus the combination of TNF $\alpha$ or MCP-1. Both cytokines dramatically increased future ethanol withdrawal-induced anxiety-like behavior ( $p<0.05$ versus controls). The CRF-1R antagonist SSR125543 administered prior to each of the two cytokine treatments mitigated this effect. Responding in these animals was significantly higher than in animals treated only with the cytokines and ethanol $(\mathrm{p}<0.05)$ and was not different from animals that received neither of these treatments $(p>0.05)$.

\subsection{Experiment 5. Demonstration that a MEK Inhibitor Blocks Stress Facilitation of Ethanol Withdrawal-Induced Anxiety}

This experiment attempted an initial probe of the potential role of the MEK pathway in the effects of stress in an ethanol withdrawal-induced anxiety model. For this experiment the MEK inhibitor SL327 was injected intraventricularly prior to each stress applied before the 5-day regimen of chronic ethanol. As shown in Figure 6, a main effect of ED/stress treatment was found, $F(1,24=4.97, \mathrm{p}<0.05$. While there was no effect of drug treatment alone ( $p>0.05)$, an interaction of ED/Stress treatment by drug treatment was found, $\mathrm{F}(1,24)$ $=12.02, \mathrm{p}<0.01$. Posthoc tests showed significant differences between the ED/Stress treated group and all other groups $(\mathrm{p}<0.05)$.

\subsection{Experiment 6: Demonstration of a TNFa Increase in Firing Rate and Release of GABA from CeA Neurons}

To assess the potential direct actions of cytokines on neuronal activity in a brain region relevant to chronic ethanol withdrawal anxiety (Huang et al., 2010), this experiment examined electrophysiological effects of TNF $\alpha$ on neurons in the central amygdala. Figure 7 shows that a stable pre-TNF $\alpha$ firing rate of an amygdala neuron was significantly increased during the acute 2-minute application of TNF $\alpha$. The percent increase in TNF $\alpha$-driven firing from the average of the pre- and post-TNFa firing rate was found to be significant with a ttest $(\mathrm{t}(21)=2.18, \mathrm{p}<0.05)$. Figure 7 also shows additional functional neuronal consequences of TNF $\alpha$ in a separate set of amygdala neurons. TNF $\alpha$ elevated presynaptically-mediated GABA release (mIPSCs) $(\mathrm{t}(22)=2.22, \mathrm{p}<0.05$ relative to non-TNF $\alpha$-exposed cells).

\section{Discussion}

The results of these experiments add to a growing body of literature showing that stress can initiate and maintain alcohol abuse as well as a variety of psychiatric disorders. Previous work demonstrated that restraint stress prior to chronic ethanol facilitated ethanol withdrawal-induced anxiety-like behavior (Breese et al., 2004). This stress was shown to elevate TNF $\alpha$ in brain, a finding consistent with previous studies showing that stress elevates brain cytokines (Deak et al., 2005; Minami et al., 1991; Nguyen et al., 1998; O'Connor et al., 2003; Shintani et al., 1995; Shizuya et al., 1997; Suzuki et al.,1997). Subsequent studies may benefit from defining potential shifts in TNF $\alpha$ dose response curves in alcohol exposed versus controls in brain regions thought to be relevant to this anxiety-like response. Likewise, defining the effect of stress on cytokine levels at additional time points, 
in more discrete brain regions, or in the presence of cytokine inhibition (e.g. antagonists) could provide further functional relevance for the effect of stress to increase TNF $\alpha$ or other cytokines in brain.

The mechanism(s) by which stress and cytokines influence ethanol action are not well understood. When chronic ethanol in adult rats is limited to 5 days, anxiety during withdrawal were minimal or absent (Breese et al., 2008; Huang et al., 2010; Overstreet et al., 2002; 2003). However, when stress, CRF, or MCP-1 or TNFa injections were applied at weekly intervals prior to this ethanol regimen (Breese et al., 2008; Huang et al., 2010; Overstreet et al., 2002; 2003), social interaction deficits were unmasked during withdrawal. These findings suggest an adaptation to these various challenges sensitizes ethanol withdrawal anxiety. Moreover, earlier work indicated that selected brain sites supported the facilitation of ethanol withdrawal anxiety (e.g., Huang et al., 2010; Knapp et al., 2007; Overstreet et al., 2006). Based upon the demonstration that cytokines administered ICV prior to chronic ethanol sensitize ethanol withdrawal anxiety (Breese et al., 2008), microinjection of TNF $\alpha$ into the amygdala was examined and shown to elevate anxiety-like behavior during ethanol withdrawal. This finding underscores the potential role of this brain site in the cumulative adaptation induced by TNF $\alpha$ that modifies the effect of chronic ethanol. Future experiments are planned to determine whether other cytokines will act in the amygdala and to define the minimal dose that affects withdrawal responses.

The results of the TNF $\alpha$ microinjections suggest that an extra-hypothalamic action of cytokines contributes to chronic ethanol effects on behavior. While administration of corticosterone to animals in an earlier study did not reproduce stress effects on ethanol withdrawal anxiety (Breese et al., 2004), it had not been tested whether this sensitizing effect of TNF $\alpha$ could relate to the HPA axis activation (Turnbull and Rivier, 1999). Thus, the present investigation sought to explore potential role of the HPA axis in the action of $\mathrm{TNF} \alpha$ by administering cytokine directly into the amygdala. This treatment did not alter plasma corticosterone (Figure 4). Thus, while enhanced cytokine function can elevate HPA axis activity (Pérez-Nievas et al., 2010; Turnbull and Rivier, 1999) and increase withdrawal anxiety (Breese et al., 2008; present data), it would be difficult to argue that the response to TNF $\alpha$ was mediated by an activated HPA axis.

One caveat in the interpretation of the anxiety phenotype in these studies is the fact that $7 \%$ $\mathrm{ED}$ (approx $10 \mathrm{~g} / \mathrm{kg} /$ day over 5 days) was used in the experiment with TNF $\alpha$ microinjection to elicit a degree of withdrawal upon which TNFa treatment could be superimposed. This treatment reduced SI behavior as well as locomotor responses such that the withdrawal response was not necessarily restricted to an anxiety-like state. While locomotor behavior was reduced in both ethanol-treated groups in the TNF $\alpha$ experiment, the most dramatic anxiety response was found in the group treated with $\mathrm{TNF} \alpha$ with limited anxiety effects on the group treated with ethanol alone. Thus, the anxiety effect and the locomotor change appear to have varied independently of each other as previously reported (Overstreet et al., 2002), and the anxiety measure does not appear to depend upon altered locomotion.

Nevertheless, subsequent ethanol-related experiments incorporated systematic modifications in the ethanol concentration and timing of behavioral measures to optimize isolation of the anxiety-like response. In this regard, reduced locomotion observed in the TNF $\alpha$ experiment with the 7\% ED is less likely to be seen with lower concentrations of ED (e.g., Knapp et al., 2007; Overstreet et al., 2002; Wills et al., 2009). That is, this effect is either not observed in these earlier experiments in which TNF $\alpha$ was administered ICV or is at best limited when in groups receive stress given prior to ethanol exposure (e.g., Table 1).

This stress-facilitated effect on withdrawal anxiety is sensitive to pharmacological manipulation (Breese et al., 2004). Among the drugs that prevented this sensitization of 
withdrawal anxiety was a CRF1R antagonist. The CRF1R antagonist SSR125543 was administered prior to ICV administration of TNF $\alpha$ and MCP-1 that were given prior to the chronic ethanol exposure to consequences on ethanol withdrawal anxiety. The ICV cytokines administered twice prior to the subthreshold chronic ethanol experience produce social interaction deficits similar to those previously reported (Breese et al., 2008). The CRF1R antagonist blocked the cytokine-induced sensitization of withdrawal anxiety. Given that the CRF1R antagonist prevents sensitization by stress as well as by CRF (Breese et al., 2004; Overstreet et al., 2004), our new results are consistent with CRF impacting cytokines (Borsody et al., 2002; del Cerro and Borrrell, 1990; Kohman et al., 2007). A schematic representation of cytokine/CRF interactions that may be involved in this response is depicted in Figure 8. This potential involvement of CRF in microglia actions is based in part on upon Wang et al. $(2002,2003)$ who demonstrated that CRF activation of CRF-1Rs on microglia facilitate release of cytokines. These and other results suggest the possibility that stress-induced release of CRF can release cytokines (Wang et al., 2002, 2003), which in turn facilitate further CRF release (del Cerro and Borrell, 1990). The results described herein extend these observations by implicating an interaction of cytokines and CRF in stress associated with alcohol withdrawal and by implicating CRF in sensitized withdrawal anxiety following repeated cytokine exposures (Figure 8). Overall, these experiments are consistent with a growing body of evidence implicating CRF in stress and chronic ethanol effects that influence emotional behavior and ethanol consumption (Breese et al., 2010; Heilig and Koob, 2007 for reviews).

CRF, as well as cytokines and LPS, have been shown to engage pERK (Hauger et al., 2009; Jara et al., 2007; Munhoz et al., 2010). The latter findings and the results herein suggest that CRF-1R and/or cytokine receptors engage signaling events that impact on adaptive responses that in turn may render animals more prone to emotional responding and more vulnerable to future challenges to stress. Therefore, it was reasoned that if cytokines, CRF, and stress influence adaptation to chronic ethanol, then perhaps this $2^{\text {nd }}$ messenger pathway is involved and that inhibition of MEK would prevent the stress-induced sensitization of the ethanol withdrawal anxiety. Results showed that SL327 administered prior to stress inhibited development of anxiety arising from ethanol withdrawal. While this experiment did not directly test whether the behavioral effects of manipulating the MEK pathway are unique to glia or to neural function, it was also shown that SL327 had no actions in controls. Additional work to assess pERK and related kinase signaling pathways in this model are warranted to further define the generalizability of the findings and the mechanisms and cell types involved in the maladaptive responses generated in the model.

Since cytokines must act on their individual receptors to influence neural function, evidence was sought for this action by determining if the actions of TNF $\alpha$ in the amygdala could be associated with direct effects of TNF $\alpha$ on neural function. Figure 7 shows that TNF $\alpha$ increased firing rates and facilitated GABA release in the $\mathrm{CeA}$, an area of the brain long known to regulate emotional behavior and ethanol withdrawal behaviors (Knapp et al., 2007; Koob, 2009). The results are consistent with the idea that direct actions of cytokines on neurons may mediate some of the effects of TNF $\alpha$ seen in our studies. This finding is consistent with a neuromodulatory action of cytokines distinct from their neuroimmune action (e.g., Adler et al., 2006; Bauer et al., 2007; Rostène et al., 2007; Shi et al., 2010). As neuromodulators, cytokines may be integral pathophysiologic contributors to drug abuse and other neurobehavioral disorders (Anisman and Merali, 2003; Dunn et al., 2005; Hayley et al., 2005; Pucak and Kaplin, 2005; Raison et al., 2006; Uddin et al., 2010). Because these physiological effects were recorded in neurons of young rats, they may not perfectly represent effects in adults. However, this demonstration of neural action is consistent with the effects of the TNF $\alpha$ observed with microinjection into the amygdala. 
Interactive effects of stress, CRF, and TNF $\alpha$ are arguably mediated by interaction of glia and neurons (Adler et al., 2006; Rostène et al., 2007; Kawasaki et al. 2008; Wilkinson et al. 1993). In this regard, a likely source of cytokine input following stress is the activation of glia (Bajetto et al., 2002), which when activated release cytokines including TNF $\alpha$ and IL1 $\beta$ (Kreutzberg, 1996). They can be activated by neurotransmitters, by immune stimulation through TLR4 receptors, or by a direct action of ethanol (Alfonso-Loeches et al., 2010; Dolganiuc et al., 2006; Rostène et al., 2007; Szabo et al., 2007). The present results show that TNF $\alpha$ can alter neural function, consistent with previous publications (Zhu et al., 2010). Thus, glial activation by stress or ethanol may release cytokines that alter neural activity at brain sites involved in anxiety-like behavior. The data showing that repeated stress or repeated cytokine microinjection into the CeA can sensitize animals to anxiety-like behavior induced by a subsequent ethanol withdrawal episode are consistent with just such a glialneuronal interaction. This interaction is supported by data showing that CRF and cytokines, which can act both on neurons and glia (e.g., Jung et al., 2008; Wang et al., 2003; Gallagher et al., 2008), can substitute for stress (Breese et al., 2004; 2008; Huang et al., 2010) and that a CRF-1 antagonist blocks the action of both cytokines and CRF (Breese et al., 2004; Huang et al., 2010; Wang et al., 2003, data herein). A requirement for such a glial-neural interaction, as the basis of the sensitization by stress, CRF, and cytokines on withdrawalinduced anxiety-like behavior, is that the cytokines are active at a brain site involved in anxiety-like behavior. The illustration of altered neuronal activity in the CeA is direct evidence for an action of cytokines at a relevant brain site. Whether CRF is the primary controller within this site for this interactive CRF-cytokine process is unknown.

Nonetheless, because glia are a part of the innate immune system in the CNS and repeated activation of glia by stress, immune challenge, CRF, or ethanol stimulation may "prime" them for production of cytokines (Anisman et al., 2003; Frank et al., 2010; Hains et al., 2010; Johnson et al., 2004), perhaps primed glia are responsible for some long-term neural consequences (Figure 8). Finally, while alcoholism is a complex chronic disorder and no single mechanism can explain uncontrolled drinking and associated consequences, the results herein support the idea that CRF and cytokines (and hence neurons and glia) interact to influence neuronal function, and thus may impact the role of stress in negative affect seen in the alcoholic.

\section{Acknowledgments}

Drs. Knapp and Overstreet contributed equally to this work. The authors wish to acknowledge Kui-Ling Huang for her excellent technical assistance and Sanofi-Aventis for the gift of SSR125543. This work was supported by AA011605, AA14949, and AA017462.

\section{References}

Adler M, Geller E, Chen X, Rogers T. Viewing chemokines as a third major system of communication in the brain. AAPS J. 2006; 7:E865-E870. [PubMed: 16594639]

Alfonso-Loeches S, Pascual-Lucas M, Blanco AM, Sanchez-Vera I, Guerri C. Pivotal role of TLR4 receptors in alcohol-induced neuroinflammation and brain damage. J. Neurosci. 2010; 30(24):82858295. [PubMed: 20554880]

Anisman H, Merali Z, Hayley S. Sensitization associated with stressors and cytokine treatments. Brain Behav. Immun. 2003; 17(2):86-93. [PubMed: 12676571]

Anisman H, Merali Z. Cytokines, stress and depressive illness: brain-immune interactions. Ann. Med. 2003; 35(1):2-11. [PubMed: 12693607]

Bajetto A, Bonavia R, Barbero S, Schettini G. Characterization of chemokines and their receptors in the central nervous system: physiopathological implications. J. Neurochem. 2002; 82(6):13111329. [PubMed: 12354279]

Bauer S, Kerr BJ, Patterson PH. The neuropoietic cytokine family in development, plasticity, disease and injury. Nature Neurosci. Rev. 2007; 8(3):221-232. 
Borsody MK, Weiss JM. Alteration of locus coeruleus neuronal activity by interleukin-1 and the involvement of endogenous corticotropin-releasing hormone. Neuroimmunomodulation. 20022003; 10(2):101-121.

Brady KT, Lydiard RB. The association of alcoholism and anxiety. Psychiatr. Quart. 1993; 64(2):135149.

Breese GR, Overstreet DH, Knapp DJ. Stress sensitization of the alcohol withdrawal-induced reduction in social interaction: inhibition by CRF-1 and benzodiazepine receptor antagonists and a 5-HT1A agonist. Neuropsychopharmacology. 2004; 29(3):470-482. [PubMed: 12955093]

Breese GR, Overstreet DH, Knapp DJ. Conceptual framework for the etiology of alcoholism: a "kindling"/stress hypothesis. Psychopharmacology (Berl). 2005; 178(4):367-380. [PubMed: 15765253]

Breese GR, Overstreet DH, Knapp DJ, Navarro M. Prior multiple ethanol withdrawals enhance stressinduced anxiety-like behavior: inhibition by CRF1- and benzodiazepine-receptor antagonists and a 5-HT1a-receptor agonist. Neuropsychopharmacology. 2005; 30(9):1662-1669. [PubMed: $15726114]$

Breese GR, Knapp DJ, Overstreet DH, Navarro M, Wills TA, Angel RA. Repeated lipopolysaccharide (LPS) or cytokine treatments sensitize ethanol withdrawal-induced anxiety-like behavior. Neuropsychopharmacology. 2008; 33(4):867-876. [PubMed: 17551540]

Breese GR, Sinha R, Heilig M. Chronic alcohol neuroadaptation and stress contribute to susceptibility for alcohol craving and relapse. Pharmacol. Ther. 2011; 129(2):149-171. [PubMed: 20951730]

Deak T, Bordner K, McElderry N, Barnum C, Blandino P Jr, Deak M, Tammariello S. Stress-induced increases in hypothalamic IL-1: systematic analysis of multiple stressor paradigms. Brain Res. Bull. 2005; 64:541-556. [PubMed: 15639551]

del Cerro S, Borrrell J. Interleukin-1 affects the behavioral despair response in rats by an indirect mechanism which requires endogenous CRF. Brain Res. 1990; 528(1):162-164. [PubMed: 2245334]

Dolganiuc A, Bakis G, Kodys K, Mandrekar P, Szabo G. Acute ethanol treatment modulates Toll-like receptor-4 association with lipid rafts. Alcohol. Clin. Exp. Res. 2006; 30(1):76-85. [PubMed: 16433734]

Dunn AJ, Swiergiel AH, de Beaurepaire R. Cytokines as mediators of depression: what can we learn from animal studies? Neurosci. Biobehav. Rev. 2005; 29(4-5):891-909. [PubMed: 15885777]

File SE, Hyde JR. Can social interaction be used to measure anxiety? Br. J. Pharmacol. 1978; 62(1): 19-24. [PubMed: 563752]

File SE, Seth P. A review of 25 years of the social interaction test. Eur. J. Pharmacol. 2003; 463(1-3): 35-53. [PubMed: 12600701]

Fox HC, Bergquist KL, Hong KI, Sinha R. Stress-induced and alcohol cue-induced craving in recently abstinent alcohol-dependent individuals. Alcohol. Clin. Exp. Res. 2007; 31(3):395-403. [PubMed: 17295723]

Frank MG, Miguel ZD, Watkins LR, Maier SF. Prior exposure to glucocorticoids sensitizes the neuroinflammatory and peripheral inflammatory responses to E. coli lipopolysaccharide. Brain Behav. Immun. 2010; 24(1):19-30. [PubMed: 19647070]

Gallagher JP, Orozco-Cabal LF, Liu J, Shinnick-Gallagher P. Synaptic physiology of central CRH system. Eur. J. Pharmacol. 2008; 583(2-3):215-225. [PubMed: 18342852]

Hains LE, Loram LC, Weiseler JL, Frank MG, Bloss EB, Sholar P, Taylor FR, Harrison JA, Martin TJ, Eisenach JC, Maier SF, Watkins LR. Pain intensity and duration can be enhanced by prior challenge: initial evidence suggestive of a role of microglial priming. J. Pain. 2010; 11(10):10041014. [PubMed: 20434956]

Hauger RL, Risbrough V, Brauns O, Dautzenberg FM. Corticotropin releasing factor (CRF) receptor signaling in the central nervous system: new molecular targets. CNS Neurol. Disord. Drug Targets. 2006; 5:453-479. [PubMed: 16918397]

Hauger RL, Risbrough V, Oakley RH, Olivares-Reyes JA, Dautzenberg FM. Role of CRF receptor signaling in stress vulnerability, anxiety, and depression. Ann. N. Y. Acad. Sci. 2009; 1179:120143. [PubMed: 19906236] 
Hayley S, Poulter MO, Merali Z, Anisman H. The pathogenesis of clinical depression: stressor- and cytokine-induced alterations of neuroplasticity. Neuroscience. 2005; 135(3):659-678. [PubMed: $16154288]$

He J, Crews FT. Increased MCP-1 and microglia in various regions of the human alcoholic brain. Exp. Neurol. 2008; 210(2):349-358. [PubMed: 18190912]

Heilig M, Koob GF. A key role for corticotropin-releasing factor in alcohol dependence. Trends Neurosci. 2007; 30(8):399-406. [PubMed: 17629579]

Huang MM, Overstreet DH, Knapp DJ, Angel RA, Wills TA, Navarro M, Rivier J, Vale WW, Breese GR. Corticotropin-releasing factor (CRF) sensitization of ethanol withdrawal-induced anxiety-like behavior is brain site specific and mediated by CRF-1 receptors: relation to stress-induced sensitization. J. Pharmacol. Exp. Ther. 2010; 332(1):298-307. [PubMed: 19843974]

Jara JH, Singh BB, Floden AM, Combs CK. Tumor necrosis factor alpha stimulates NMDA receptor activity in mouse cortical neurons resulting in ERK-dependent death. J. Neurochem. 2007; 100(5): 1407-1420. [PubMed: 17241124]

Johnson JD, O'Connor KA, Watkins LR, Maier SF. The role of IL-1beta in stress-induced sensitization of proinflammatory cytokine and corticosterone responses. Neuroscience. 2004; 127(3):569-577. [PubMed: 15283957]

Jung H, Toth PT, White FA, Miller RJ. Monocyte chemoattractant protein-1 functions as a neuromodulator in dorsal root ganglia neurons. J. Neurochem. 2008; 104(1):254-263. [PubMed: 17944871]

Kawasaki Y, Zhang L, Cheng JK, Ji RR. Cytokine mechanisms of central sensitization: distinct and overlapping role of interleukin-1beta, interleukin-6, and tumor necrosis factor-alpha in regulating synaptic and neuronal activity in the superficial spinal cord. J. Neurosci. 2008; 28(20):5189-5194. [PubMed: 18480275]

Knapp DJ, Overstreet DH, Breese GR. Modulation of ethanol withdrawal-induced anxiety-like behavior during later withdrawals by treatment of early withdrawals with benzodiazepine/gammaaminobutyric acid ligands. Alcohol. Clin. Exp. Res. 2005; 29(4):553-563. [PubMed: 15834220]

Knapp DJ, Overstreet DH, Angel RA, Navarro M, Breese GR. The amygdala regulates the antianxiety sensitization effect of flumazenil during repeated chronic ethanol or repeated stress. Alcohol. Clin. Exp. Res. 2007; 31(11):1872-1882. [PubMed: 17908266]

Kohman RA, Tarr AJ, Sparkman NL, Day CE, Paquet A, Akkaraju GR, Boehm GW. Alleviation of the effects of endotoxin exposure on behavior and hippocampal IL-1beta by a selective nonpeptide antagonist of corticotropin-releasing factor receptors. Brain Behav. Immun. 2007; 21(6): 824-835. [PubMed: 17339098]

Koob GF. Brain stress systems in the amygdala and addiction. Brain Res. 2009; 1293:61-75. [PubMed: 19332030]

Koob GF. The role of CRF and CRF-related peptides in the dark side of addiction. Brain Res. 2010; 1314:3-14. [PubMed: 19912996]

Kreutzberg GW. Microglia: a sensor for pathological events in the CNS. Trends Neurosci. 1996; 19(8):312-318. [PubMed: 8843599]

Lowery EG, Thiele TE. Pre-clinical evidence that corticotropin-releasing factor (CRF) receptor antagonists are promising targets for pharmacological treatment of alcoholism. CNS Neurol. Disord. Drug Targets. 2010; 9(1):77-86. [PubMed: 20201818]

Minami M, Kuraishi Y, Yamaguchi T, Nakai S, Hirai Y, Satoh M. Immobilization stress induces interleukin-1 beta mRNA in the rat hypothalamus. Neurosci. Lett. 1991; 123(2):254-256. [PubMed: 2027540]

Munhoz CD, Sorrells SF, Caso JR, Scavone C, Sapolsky RM. Glucocorticoids exacerbate lipopolysaccharide-induced signaling in the frontal cortex and hippocampus in a dose-dependent manner. J. Neurosci. 2010; 30(41):13690-13698. [PubMed: 20943909]

Nguyen KT, Deak T, Owens SM, Kohno T, Fleshner M, Watkins LR, Maier SF. Exposure to acute stress induces brain IL-1 $\beta$ protein in the rat. J. Neurosci. 1998; 18(6):2239-2246. [PubMed: 9482808] 
O'Connor KA, Johnson JD, Hansen MK, Wieseler Frank JL, Maksimova E, Watkins LR, Maier SF. Peripheral and central proinflammatory cytokine response to a severe acute stressor. Brain Res. 2003; 991(1-2):123-132. [PubMed: 14575884]

Overstreet DH, Knapp DJ, Breese GR. Accentuated decrease in social interaction in rats subjected to repeated ethanol withdrawals. Alcohol. Clin. Exp. Res. 2002; 6(8):1259-1268. [PubMed: 12198403]

Overstreet DH, Knapp DJ, Moy SS, Breese GR. A 5-HT1A agonist and a 5-HT2c antagonist reduce social interaction deficit induced by multiple ethanol withdrawals in rats. Psychopharmacology (Berl). 2003; 167(4):344-352. [PubMed: 12677355]

Overstreet DH, Knapp DJ, Breese GR. Modulation of multiple ethanol withdrawal-induced anxietylike behavior by CRF and CRF1 receptors. Pharmacol. Biochem. Behav. 2004; 77(2):405-413. [PubMed: 14751471]

Overstreet DH, Knapp DJ, Angel RA, Navarro M, Breese GR. Reduction in repeated ethanolwithdrawal-induced anxiety-like behavior by site-selective injections of 5-HT1A and 5-HT2C ligands. Psychopharmacology (Berl). 2006; 187(1):1-12. [PubMed: 16767411]

Paxinos, G.; Watson, C. The Rat Brain in Stereotaxic Coordinates. Burlington, MA: Elsevier Academic Press; 2005.

Pérez-Nievas BG, Madrigal JL, García-Bueno B, Zoppi S, Leza JC. Corticosterone basal levels and vulnerability to LPS-induced neuroinflammation in the rat brain. Brain Res. 2010; 1315:159-168. [PubMed: 20026014]

Plata-Salaman CR, Borkoski JP. Chemokines/intercrines and central regulation of feeding. Am. J. Physiol. 1994; 266(Part 2):R1711-R1715. [PubMed: 7515592]

Plata-Salaman CR, Sonti G, Borkoski JP, Wilson CD, French-Mullen JM. Anorexia induced by chronic central administration of cytokines at estimated pathophysiological concentrations. Physiol. Behav. 1996; 60:867-875. [PubMed: 9110949]

Pohorecky LA. Stress and alcohol interaction: an update of human research. Alcohol. Clin. Exp. Res. 1991; 15(3):438-459. [PubMed: 1898494]

Pohorecky LA. The interaction of alcohol and stress. A review. Neurosci. Biobehav. Rev. 1981; 5(2): 209-229. [PubMed: 6115346]

Pucak ML, Kaplin Al. Unkind cytokines: current evidence for the potential role of cytokines in immune-mediated depression. Int. Rev. Psychiatry. 2005; 17(6):477-483. [PubMed: 16401546]

Qin L, He J, Hanes RN, Pluzarev O, Hong JS, Crews FT. Increased systemic and brain cytokine production and neuroinflammation by endotoxin following ethanol treatment. $\mathrm{J}$ Neuroinflammation. 2008; 5:10. [PubMed: 18348728]

Raison CL, Capuron L, Miller AH. Cytokines sing the blues: inflammation and the pathogenesis of depression. Trends Immunol. 2006; 27(1):24-31. [PubMed: 16316783]

Regier DA, Farmer ME, Rae DS, Locke BZ, Keith SJ, Judd LL, Goodwin FK. Comorbidity of mental disorders with alcohol and other drug abuse. Results from the Epidemiologic Catchment Area (ECA) Study. JAMA. 1990; 264(19):2511-2518. [PubMed: 2232018]

Rostène W, Kitabgi P, Parsadaniantz SM. Chemokines: a new class of neuromodulator? Nat. Rev. Neurosci. 2007; 8(11):895-903. [PubMed: 17948033]

Shi P, Raizada MK, Sumners C. Brain cytokines as neuromodulators in cardiovascular control. Clin. Exp. Pharmacol. Physiol. 2010; 37(2):e52-e57. [PubMed: 19566837]

Shintani F, Nakaki T, Kanba S, Kato R, Asai M. Role of interleukin-1 in stress responses. A putative neurotransmitter. Mol. Neurobiol. 1995; 10(1):47-71. [PubMed: 7598832]

Shizuya K, Komori T, Fujiware R, Miyahara S, Ohmori M, Nomura J. The influence of restraint stress on the expression of mRNAs for IL- 6 and the IL-6 receptor in the hypothalamus and midbrain of the rat. Life Sci. 1997; 61(10):PL 135-PL 140.

Sinha R, Li CS. Imaging stress- and cue-induced drug and alcohol craving: association with relapse and clinical implications. Drug Alcohol Rev. 2007; 26(1):25-31. [PubMed: 17364833]

Sinha R, Fox HC, Hong KA, Bergquist K, Bhagwagar Z, Siedlarz KM. Enhanced negative emotion and alcohol craving, and altered physiological responses following stress and cue exposure in alcohol dependent individuals. Neuropsychopharmacology. 2009; 34(5):1198-1208. [PubMed: 18563062] 
Smith RJ, Aston-Jones G. Noradrenergic transmission in the extended amygdala: role in increased drug-seeking and relapse during protracted drug abstinence. Brain Struct. Funct. 2008; 213(1-2): 43-61. [PubMed: 18651175]

Suzuki E, Shintani F, Kanba S, Asai M, Nakaki T. Immobilization stress increases mRNA levels of interleukin-1 receptor antagonist in various rat brain regions. Cell. Mol. Neurobiol. 1997; 17(5): 557-562. [PubMed: 9353596]

Szabo G, Dolganiuc A, Dai Q, Pruett SB. TLR4, ethanol, and lipid rafts: a new mechanism of ethanol action with implications for other receptor-mediated effects. J. Immunol. 2007; 178(3):1243-1249. [PubMed: 17237368]

Turnbull AV, Rivier CL. Regulation of the hypothalamic-pituitary-adrenal axis by cytokines: actions and mechanisms of action. Physiol. Rev. 1999; 79(1):1-71. [PubMed: 9922367]

Uddin M, Aiello AE, Wildman DE, Koenen KC, Pawelec G, de Los Santos R, Goldmann E, Galea S. Epigenetic and immune function profiles associated with posttraumatic stress disorder. Proc. Natl. Acad. Sci. 2010; 107(20):9470-9475. [PubMed: 20439746]

Valdez GR, Roberts AJ, Chan K, Davis H, Brennan M, Zorrilla EP, Koob GF. Increased ethanol selfadministration and anxiety-like behavior during acute ethanol withdrawal and protracted abstinence: regulation by corticotropin-releasing factor. Alcohol. Clin. Exp. Res. 2002; 26(10): 1494-1501. [PubMed: 12394282]

Wang W, Ji P, Dow KE. Corticotrophin-releasing hormone induces proliferation and TNF-alpha release in cultured rat microglia via MAP-kinase signalling pathways. J. Neurochem. 2003; 84:189-195. [PubMed: 12485415]

Wang W, Ji P, Riopelle RJ, Dow KE. Functional expression of corticotrophin-releasing hormone $(\mathrm{CRH})$ receptor 1 in cultured rat microglia. J. Neurochem. 2002; 80(2):287-294. [PubMed: 11902119]

Wilkinson MF, Mathieson WB, Pittman QJ. Interleukin-1 $\beta$ has excitatory effects on neurons of the BNST. Brain Res. 1993; 625:342-346. [PubMed: 8275318]

Wills TA, Knapp DJ, Overstreet DH, Breese GR. Differential dietary ethanol intake and blood ethanol levels in adolescent and adult rats: effects on anxiety-like behavior and seizure thresholds. Alcohol. Clin. Exp. Res. 2008; 32(8):1350-1360. [PubMed: 18540921]

Wills TA, Knapp DJ, Overstreet DH, Breese GR. Sensitization, duration, and pharmacological blockade of anxiety-like behavior following repeated ethanol withdrawal in adolescent and adult rats. Alcohol. Clin. Exp. Res. 2009; 33(3):455-463. [PubMed: 19120055]

Zhang Z, Morse AC, Koob GF, Schulteis G. Dose- and time-dependent expression of anxiety-like behavior in the elevated plus-maze during withdrawal from acute and repeated intermittent ethanol intoxication in rats. Alcohol. Clin. Exp. Res. 2007; 31(11):1811-1819. [PubMed: 17877783]

Zhu W, Zheng H, Shao X, Wang W, Yao Q, Li Z. Excitotoxicity of TNFalpha derived from KA activated microglia on hippocampal neurons in vitro and in vivo. J. Neurochem. 2010; 114(2): 386-396. [PubMed: 20438614] 

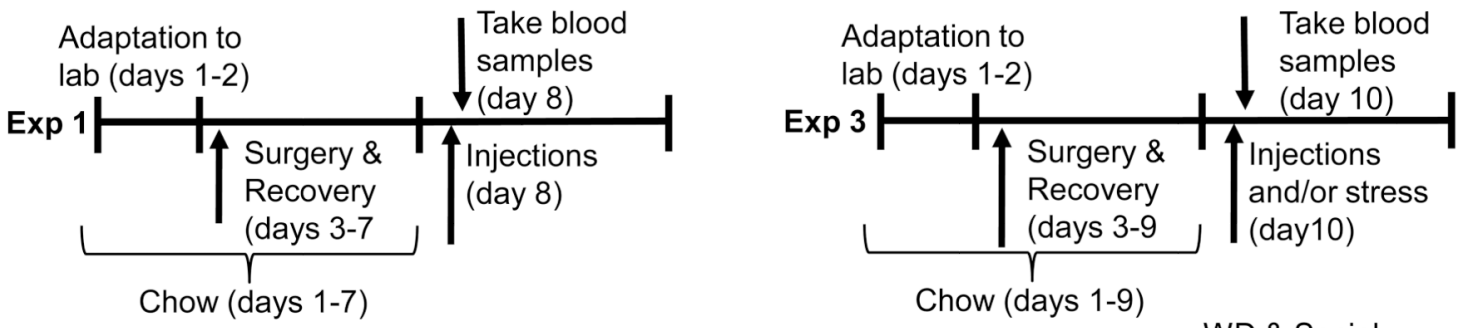

Chow (days 1-9)

Adaptation to

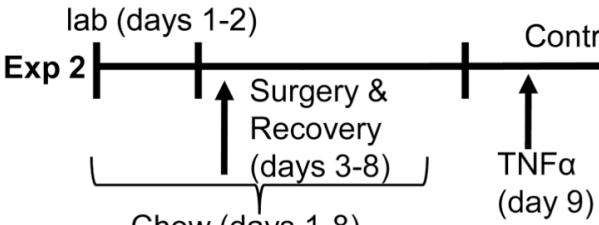

Control Diet (days 6-14)

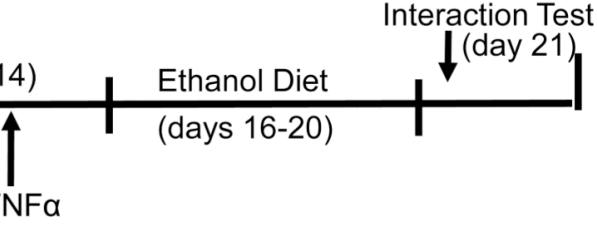

Chow (days 1-8)

(day 15)

Adaptation to

Exp 4

lab (days 1-7)

L_ Control Diet (days 11-23)

Surgery \&

Recovery (days 8-10)

Chow (days 1-10)

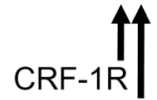

Cytokine

(day 17)

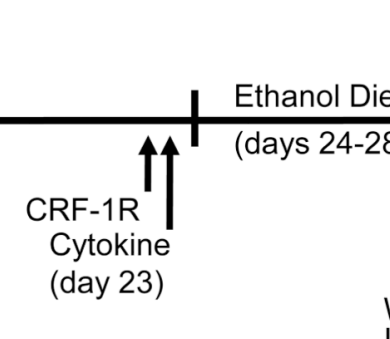

Adaptation to

$\operatorname{Exp} 5$

\begin{tabular}{l|l} 
lab (days 1-7) & Control Diet (days 11-20) \\
\hline
\end{tabular}

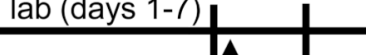

Surgery \&
Recovery (days 8-10)

Chow (days 1-10)
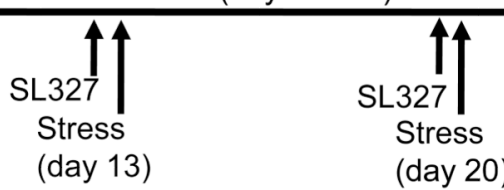

WD \& Social Interaction Test

Figure 1.

Protocols for the experiments described herein. 


\section{Induction of TNFa in Rat Brain}

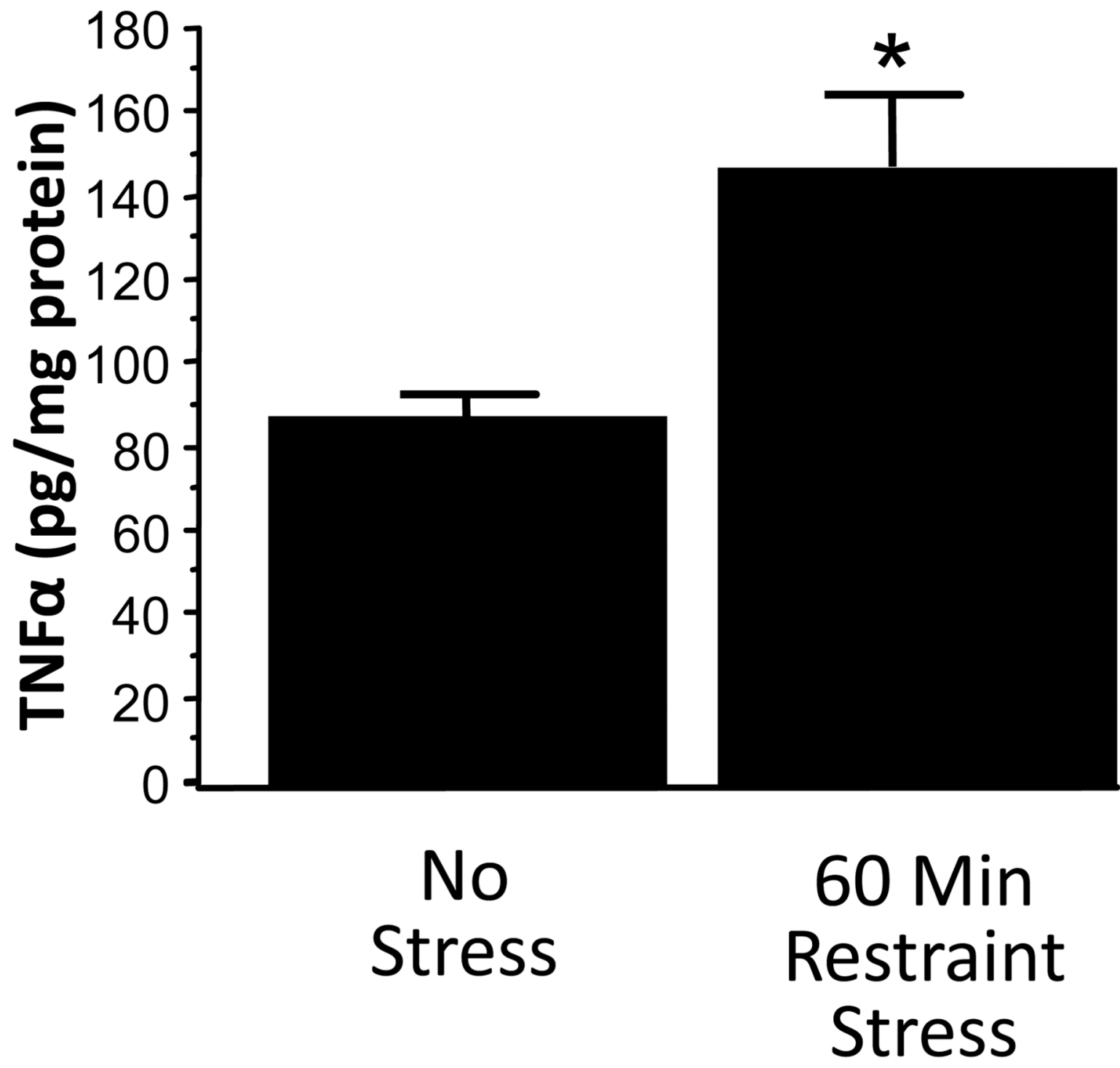

Figure 2.

$\mathrm{TNF} \alpha$ levels in brain 4.5 hours after termination of 1 hour of restraint stress. ${ }^{*} \mathrm{p}<0.05$ versus No Stress. 


\section{TNF $\alpha$ in the central amygdala sensitizes ethanol withdrawal anxiety}

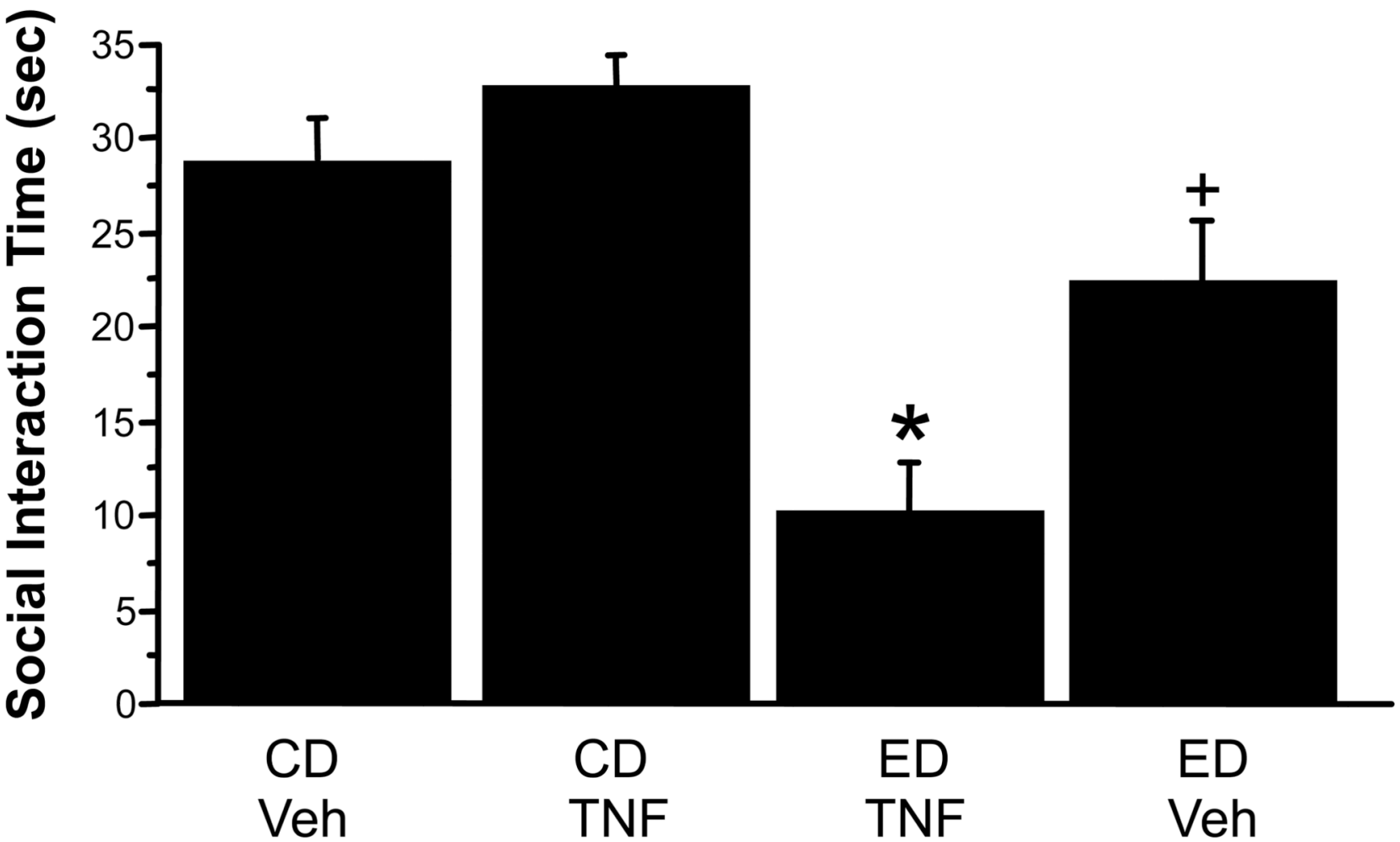

Figure 3.

Intra-amygdala injections of TNF $\alpha(10 \mathrm{ng})$ sensitize ethanol withdrawal anxiety in the rat. Veh $=$ artificial cerebrospinal fluid. ${ }^{*} \mathrm{p}<0.05$ vs Control Diet/Veh; ${ }^{+}<0.05$ vs Ethanol Diet/ $\mathrm{TNF} \alpha . \mathrm{CD}=$ control diet; $\mathrm{ED}=$ ethanol diet. 


\section{Intra-amygdala TNFa (100 ng) does not Increase Plasma Corticosterone Levels}

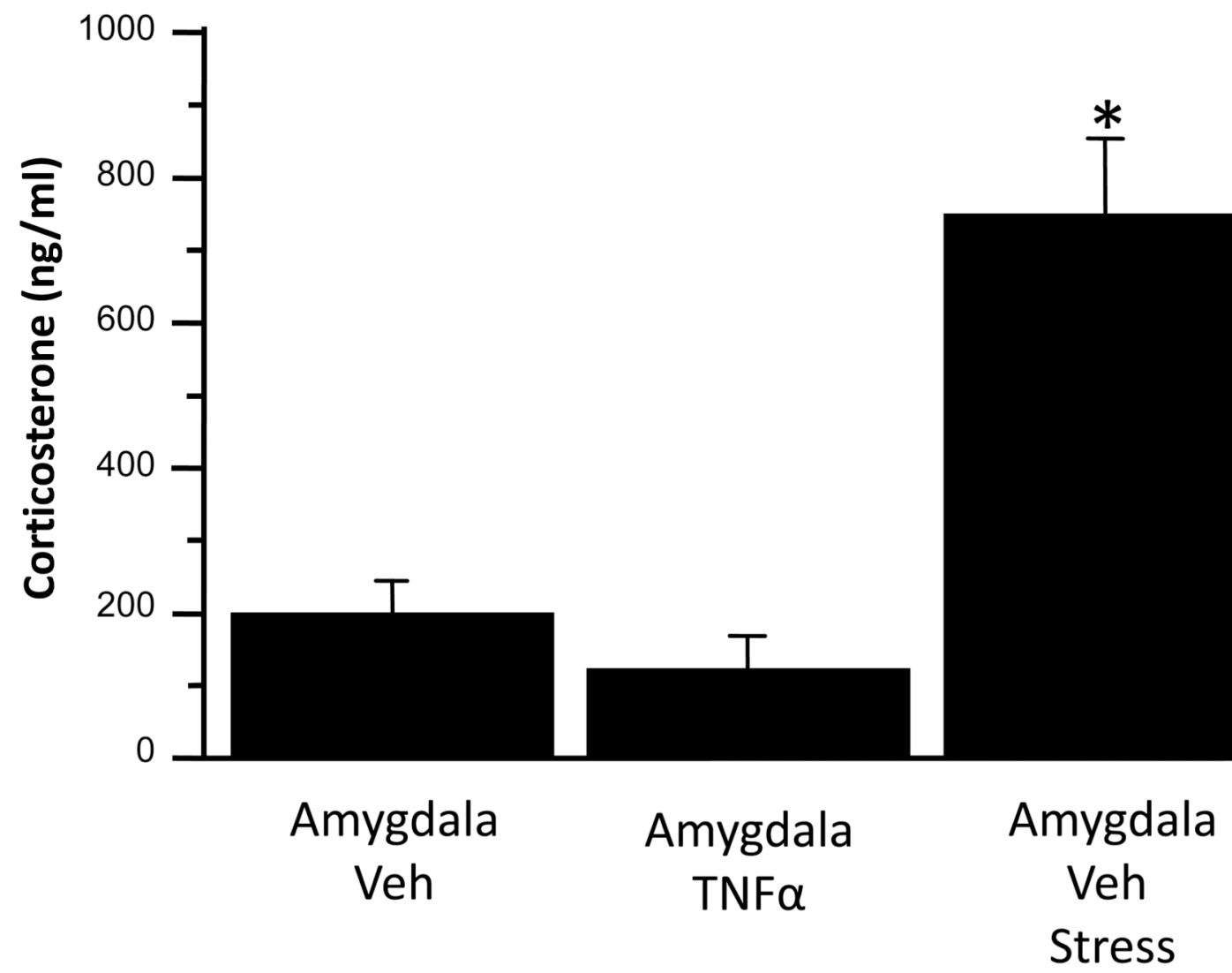

Figure 4.

Intra-amygdala TNF $\alpha$ (100 ng in $0.5 \mathrm{ul}$ ) fails to increase plasma corticosterone. Nonstressed rats were injected with vehicle (aCSF) or TNF $\alpha 45$ min prior to blood sampling. Stressed rats were injected with vehicle 30 minutes prior to $30 \mathrm{~min}$ restraint, then their blood sampled 30 minutes after cessation of stress. ${ }^{*} \mathrm{p}<0.05$ versus other groups. 


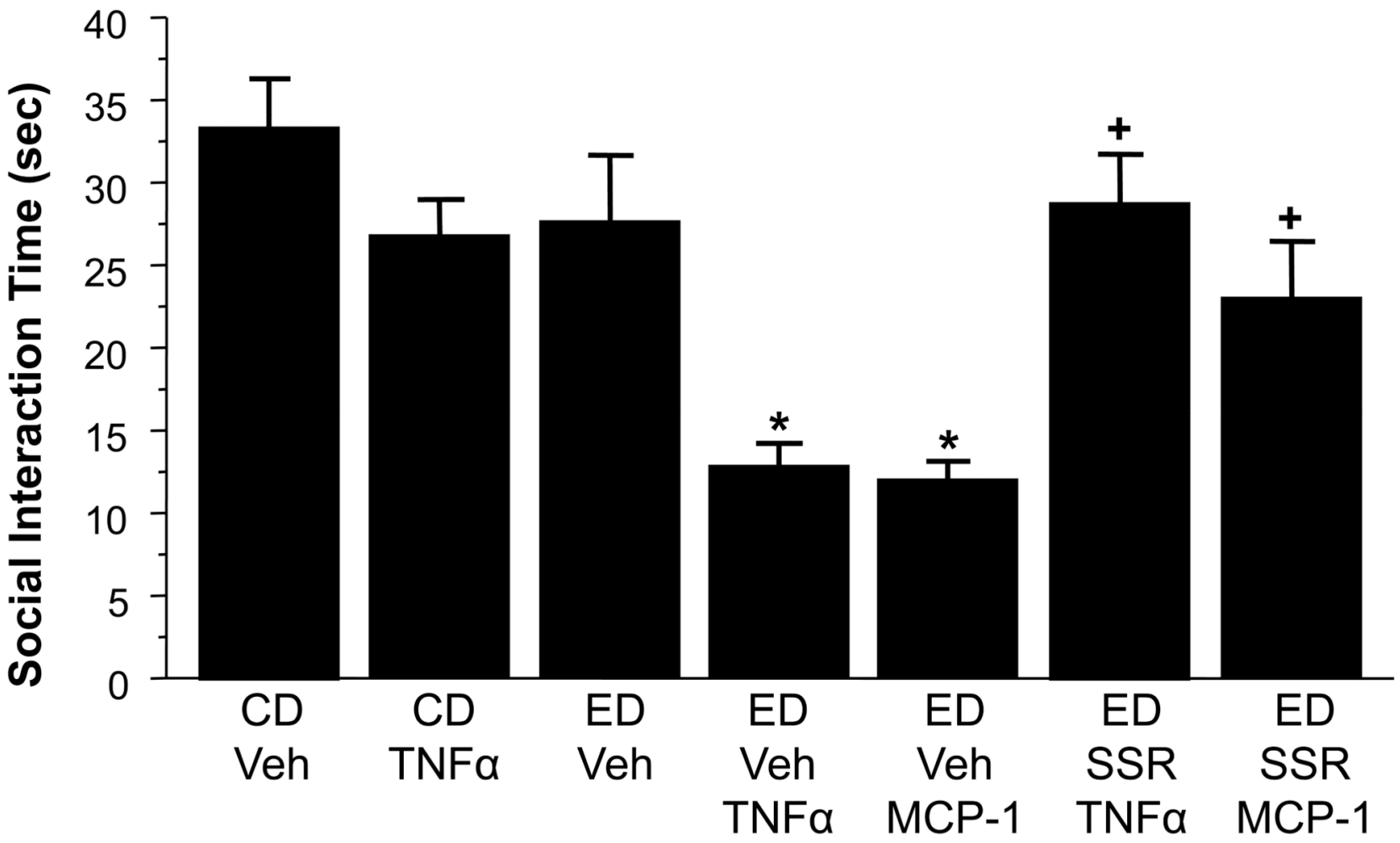

Figure 5.

A CRF-1R antagonist blocks the sensitizing effect of cytokines (MCP-1 or TNF $\alpha$; $100 \mathrm{ng}$ ICV) on ethanol withdrawal anxiety. Rats were administered SSR125543 prior to either cytokine during each of the first two of three ethanol withdrawal periods. Behavior was recorded during the third withdrawal. $\mathrm{CD}=$ control diet; $\mathrm{ED}=$ ethanol diet, $* \mathrm{p}<0.05 \mathrm{vs} \mathrm{CD} /$ Veh; $+<0.05$ vs ED-TNF $\alpha$ or ED-MCP-1. 
A MEK inhibitor blocks stress effects on ethanol withdrawal
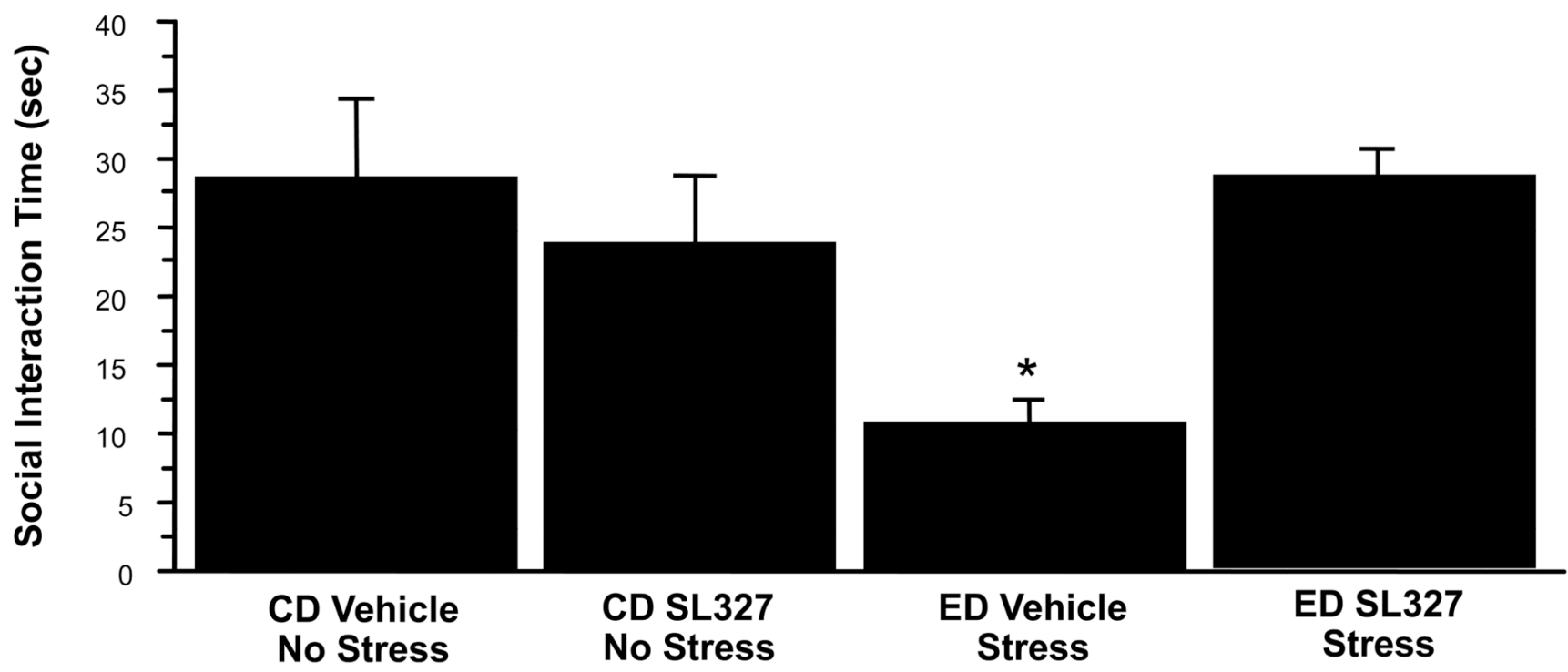

Figure 6.

ICV administration of the MEK inhibitor SL327 blocks anxiety-like behavior induced by a stress-sensitized ethanol withdrawal protocol in rats. *p $<0.05$ Compared to other treatments. $\mathrm{ED}=$ ethanol diet $\mathrm{CD}=$ control diet, Vehicle = artificial cerebrospinal fluid. 
TNFa [1.25 nM] Increases Firing Rate and GABA Release in CeA Neurons in Brain Slices.

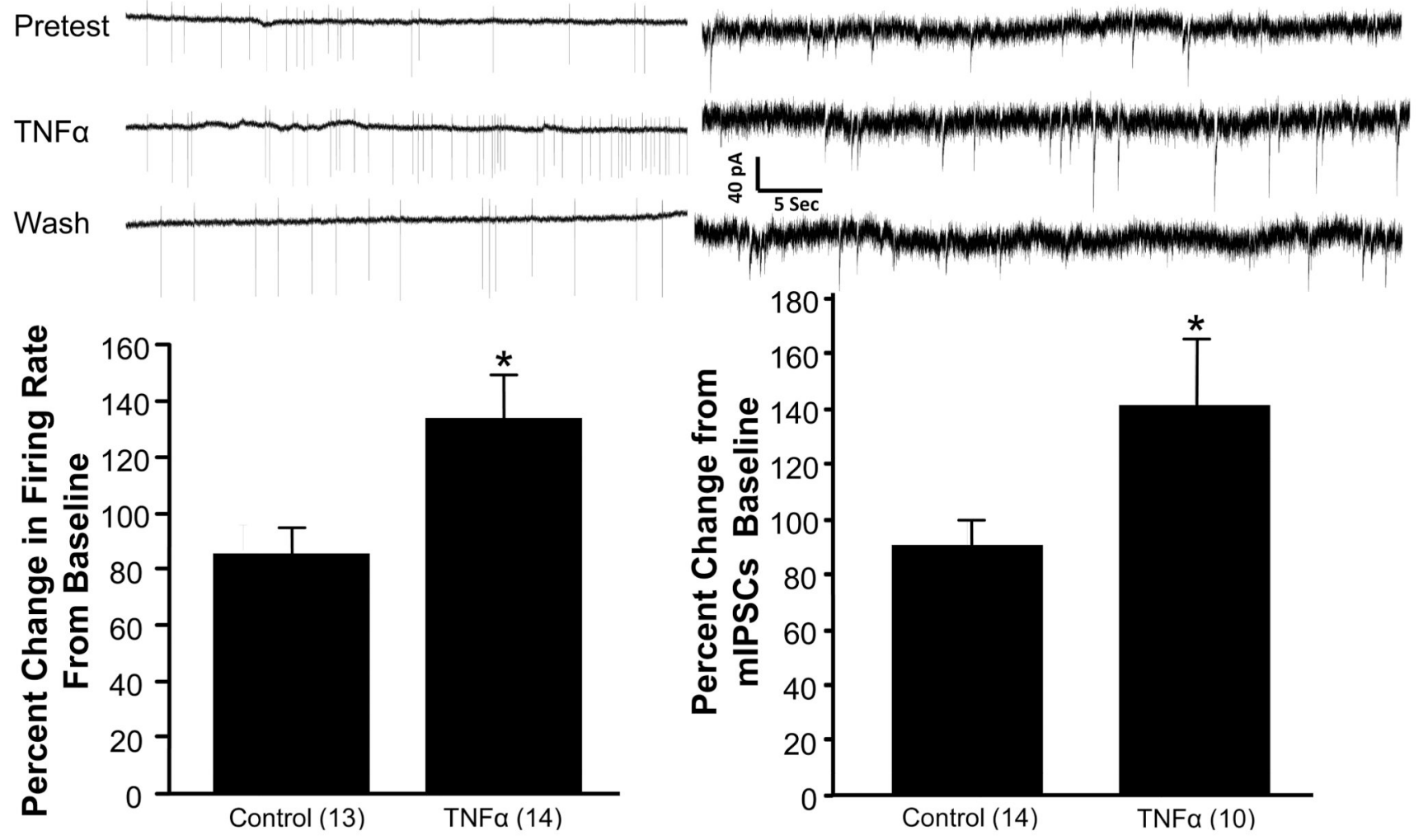

Figure 7.

Physiological responses of amygdala neurons to TNF $\alpha$. Representative neuronal firing rates in a neuron from an amygdala slice preparation before, during and after TNF $\alpha(1.25 \mathrm{nM})$ exposure (upper left panel). The firing rate increase relative to the average of the pre and post-TNF $\alpha$ periods was significantly greater than rates obtained from non-TNF $\alpha$ exposed cells. A similar comparison of the effect of TNF $\alpha(1.25 \mathrm{nM})$ on GABA release in the amygdala slice is shown in the lower right panel lower right panel). Representative traces of mIPSCs are shown before, during, and after TFN $\alpha$ in the upper right panel. Numbers in parentheses are number of cells. mIPSCs $=$ mini inhibitory post-synaptic currents. ${ }^{*} \mathrm{p}<0.05$ versus control. 


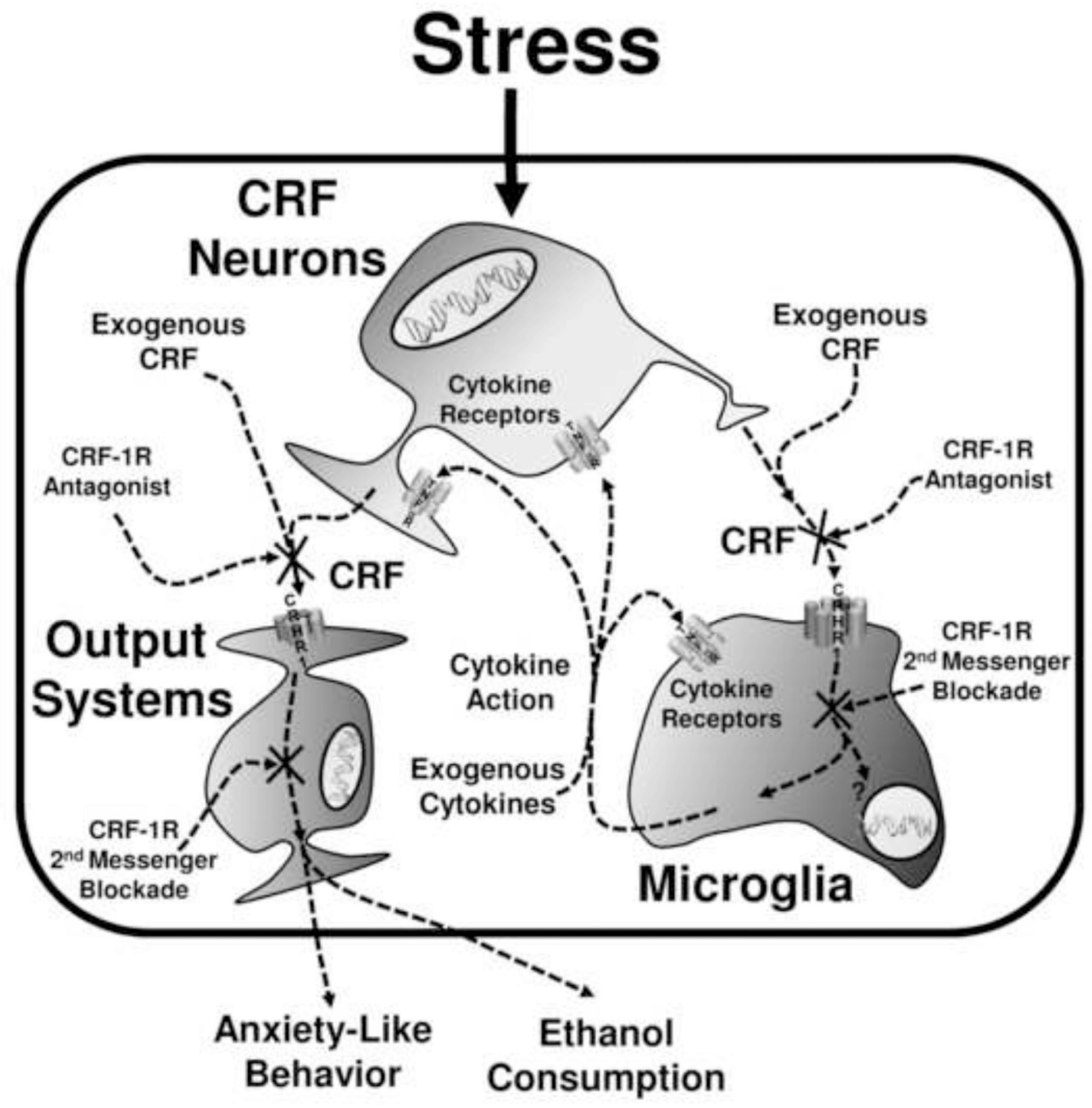

Figure 8. 
Table 1

Ethanol intakes, locomotor behavior and final body weights.

\begin{tabular}{|c|c|c|c|}
\hline & $\begin{array}{c}\text { Alcohol } \\
\text { Intake } \\
\text { (g/kg/day) }\end{array}$ & $\begin{array}{c}\text { Locomotor } \\
\text { Activity } \\
\text { (Crosses } / 5 \text { min) }\end{array}$ & $\begin{array}{c}\text { Body Weight } \\
\text { (g) }\end{array}$ \\
\hline \multicolumn{4}{|l|}{ Experiment 2} \\
\hline CD Veh $(10)^{* *}$ & -- & $131 \pm 6$ & $242 \pm 5$ \\
\hline $\mathrm{CD} \mathrm{TNF} \alpha(10)$ & -- & $129 \pm 7$ & $246 \pm 6$ \\
\hline $\mathrm{ED} \mathrm{TNF} \alpha(9)$ & $10.2 \pm 0.2$ & $59 \pm 6^{*}$ & $247 \pm 6$ \\
\hline \multirow[t]{2}{*}{ ED Veh (9) } & $10.2 \pm 0.3$ & $58 \pm 10^{*}$ & $239 \pm 4$ \\
\hline & $t(16)^{+}=N S$ & $* * * F(1,34)=97.1, \mathrm{p}<0.0001$ & $* * * F(1,34)=N S$ \\
\hline \multicolumn{4}{|l|}{$* \mathrm{p}<0.05$ vs either $\mathrm{CD}$ group } \\
\hline \multicolumn{4}{|l|}{ Experiment 4} \\
\hline CD Veh (8) & -- & 165 & $281 \pm 4$ \\
\hline $\mathrm{CD} \mathrm{TNF} \alpha(8)$ & -- & 160 & $293 \pm 4$ \\
\hline ED Veh (8) & $7.6 \pm 0.5$ & 129 & $267 \pm 8$ \\
\hline ED Veh TNF $\alpha(8)$ & $8.0 \pm 0.2$ & 159 & $292 \pm 7$ \\
\hline ED Veh MCP-1 (8) & $7.6 \pm 0.3$ & 140 & $305 \pm 7^{*}$ \\
\hline ED SSR TNF $\alpha(8)$ & $7.9 \pm 0.3$ & 136 & $274 \pm 9$ \\
\hline \multirow[t]{2}{*}{ ED SSR MCP-1 (10) } & $7.9 \pm 0.2$ & 150 & $281 \pm 9$ \\
\hline & $\mathrm{F}(4,38)=\mathrm{NS}$ & $\mathrm{F}(6,52)=\mathrm{NS}$ & $\mathrm{F}(6,52)=2.93(\mathrm{p}<0.05)$ \\
\hline \multicolumn{4}{|c|}{$*$ Significantly different from CD Veh control $(\mathrm{p}<0.05)$} \\
\hline \multicolumn{4}{|l|}{ Experiment 5} \\
\hline CD Veh No Stress (7) & -- & $107 \pm 13$ & $318 \pm 7$ \\
\hline CD SL327 No Stress (7) & -- & $104 \pm 11$ & $310 \pm 8$ \\
\hline ED Vehicle Stress (7) & $7.5 \pm 0.1$ & $78 \pm 8$ & $318 \pm 11$ \\
\hline \multirow[t]{2}{*}{ ED SL327 Stress (7) } & $7.7 \pm 0.4$ & $78 \pm 8$ & $315 \pm 7$ \\
\hline & $t(12)=N S$ & ${ }^{* * *} \mathrm{~F}(1,24)=7.47, \mathrm{p}<0.05$ & $* * * \mathrm{~F}(1,24)=\mathrm{NS}$ \\
\hline
\end{tabular}

NS $=$ non-significant ANOVA or t-test,

**

numbers in parentheses are $\mathrm{n}$ sizes per group;

${ }^{+}$numbers in parentheses are degrees of freedom.

$\mathrm{CD}=$ control diet $\mathrm{ED}=$ ethanol diet;

***

main effect of ED exposed groups.

NS $=$ not significant 